\title{
Multi-criteria Evaluation of the Intelligent Dashboard for SME Managers based on Scorecard Framework
}

\author{
Mirosław Dyczkowski, Jerzy Korczak, Helena Dudycz \\ Wroclaw University of Economics \\ ul. Komandorska 118/120 53-345 Wroclaw, Poland \\ Email: \{miroslaw.dyczkowski, jerzy.korczak, helena.dudycz, \}@ue.wroc.pl
}

\begin{abstract}
The article presents an approach to evaluate the Decision Support System applied in the InKoM project. The evaluation method is based on a scorecard framework, oriented towards Business Intelligence (BI) systems and projects dedicated to the management supporting of small and medium enterprises (SME). To design the method, known existing commercial and nocommercial BI maturity models, usability standards, and scorecard frameworks have been analyzed and adapted to SMEs area. Notably, the scorecard framework was extended to the new evaluation criteria associated with innovative knowledge-based functions created in the InKoM project, especially such as ontologies of economic and financial knowledge, and visual navigation and exploratory interface based on topic maps. The main elements of the scorecard framework and usage in InKoM of multi-criteria evaluation are illustrated and discussed in this paper.
\end{abstract}

\section{INTRODUCTION}

$\mathrm{T}$ he current economic situation forces the decisionmakers of small and medium enterprises (SMEs) to have at their disposal current and appropriate knowledge about the economic and financial situation of the enterprise and its environment. Because of that, decisionmakers must have the efficient methods and tools to identify and analyze key performance indicators that have an impact on the operations of the enterprise. Analysis and interpretation of information in the traditional way becomes very difficult, sometimes even impossible. Discovering all dependences between various financial ratios is necessary, because they alert managers about anomalies and dangers (see [23]). Decision-makers in these enterprises, in comparison to managers of big companies, may not have access to all essential strategic information. Usually financial expertise is either not available or too expensive. Big companies have at their disposal strategic consultation and possess standard procedures to solve problems in the case of essential changes in the business environment. For financial and personnel reasons most SMEs cannot afford

This work has been supported by the National Research and Development Centre within the Innotech program (track In-Tech), grant agreement INNOTECH-K1/IN1/34/153437/NCBR/12. these types of facilities. It should be noted that SMEs operate in a definitely more uncertain and risky environment than big enterprises, because of a complex and dynamic market that has a much more important impact on SMEs' financial situation than on big companies'. Tolerance of mistakes is narrower (see among others [11, pp. 74-91]). In these circumstances, SMEs' decisionmakers often act intuitively and as a result, the rationality of their decisions is significantly weaker. Moreover, SMEs' decision-makers often do not have a solid knowledge of economics and finance.

In general, most existing Business Intelligence (BI) and Executive Information Systems (EIS) provide the functionality of data aggregation and visualization (see among others [26], [31]). Many reports and papers in this domain underline the fact that decision makers expect new ICT solutions to interactively provide not only relevant and up-to-date information on the economic and financial situation of their companies, but also explanations taking into account the contextual relationships.

The aim of this article is to present the approach to multicriteria evaluation of BI innovative functions created and used in the Intelligent Dashboard for Managers (further referred to as InKoM). The InKoM system has been developed by the consortium consisting of the Wroclaw University of Economics (WUE), which is the leader, and a company UNIT4 TETA BI Center Ltd. (TETA BIC). Credit Agricole Bank Polska S.A. also participates in the project.

Figure 1 presents the main components of the InKoM: a comprehensive description of the TETA BI system with examples of its application is available on the website: [27] (see also UNIT4 TETA presentations [1], [29] and other papers published by the authors; see among others [17], [18], [19], [20]). It can be seen that the InKoM uses TETA BI mechanisms for extracting source data from ERP and non-ERP transactional systems internally (ETL), its data warehouse, and analytical database. However, the available solutions - in particular the standard analyses, reports and analytical statements generated by the system - are complemented by economic and financial knowledge - most 




Fig. 1. Components of the Intelligent Dashboard for Managers and their location in the TETA BI system (The InKoM components are shaded in grey)

importantly ontologies and topic maps - and financial data mining algorithms, including mechanisms for extracting business knowledge from the deep Web (indicated as gray color boxes). This enables a dynamic, on-line, interactive analysis of key business indicators.

The transactional data obtained from external sources, supplemented with planning data, e.g., budgets in the form of multidimensional data structures, or cubes, which are stored in a TETA BI Analysis Services database and provide a basis for the on-line, interactive creation of standard analytical queries and/or reports. The InKoM system complements and extends these processes ${ }^{1}$. By providing economic and financial knowledge stored in ontologies and presented in the form of topic maps to facilitate the perception of concepts, InKoM can make the analysis more comprehensive and simpler. This is particularly important for users who are not specialists in the analysis and interpretation of economics and finance.

The structure of the paper is the following: In the next section the overview of approaches to evaluation BI systems and projects evaluation is briefly described. The third section presents the discussion about extension of criteria of evaluation for BI functions oriented on SMEs. To illustrate the use of the extended scorecard framework, a case study of the InKoM Dashboard evaluation is characterized in the fourth section. The last section summarizes the work

\footnotetext{
${ }^{1}$ The InKoM architecture and functionalities have been presented in [17], [18], [19], [20].
}

already carried out and points out the most important conclusions.

\section{AN OVERVIEW OF APPROACHES TO BI SYSTEMS AND PROJECTS EVALUATION.}

The main goal of any BI system is to access the right data at the right time to allow proactive decision-making (see among others [6], [34]). The users of BI systems expect access to useful information and knowledge through an interface easy to understand and use $\mathrm{e}^{2}$. However, most of existing BI solutions are designed primarily for users who are able to understand the business data models and semantic and/or algorithmic relationships between financial and economic objects/concepts (data, information, measure, key performance indicator, gauge etc.) used in analytical processes. Today the development of new BI systems is oriented towards BI 2.0 (using semantic search) and 3.0, Service Oriented Architecture (SOA), Software as a Service (SaaS), mobile BI, Big Data technologies using BI etc. (see among others [14], [23], [26], [32]). The typical features of the systems include: proactive alerts and notifications, event driven (real time) access to information, advanced and predictive analytics, mobile and ubiquitous access, improved visualization, and semantic search information.

\footnotetext{
${ }^{2}$ Generally the BI system interface should allow users to do: "find what they need, understand what they find, and act appropriately, within the limits of time and effort that they consider adequate for the task" (http://www.dataprix.com/en/bi-usability-evolution-and-tendencies).
} 
But no matter what BI applications we implement, they should always meet the expectations and needs of their business users. Helpful in achieving these goals can be the systematic, continuous and multi-criteria evaluation of BI systems and projects based on formalized and verified in practice approaches to $\mathrm{BI}$ evaluation process [8]. The most important of these are:

1. BI Maturity Models,

2. BI commercial and non-commercial frameworks used to compare BI systems, projects and/or vendors,

3. BI scorecards,

4. Standards of BI systems and/or projects usability and quality,

5. Methods and tools dedicated for evaluation of economic efficiency of BI systems and/or projects.

There are many Business Intelligence Maturity Models (BI MM) developed by different authors such as Business intelligence Development Model (BIDM), TDWI's maturity model, Business Intelligence Maturity Hierarchy, Hewlett Package Business Intelligence Maturity Model, Gartner's Maturity Models, Business Information Maturity Model, AMR Research's Business Intelligence and Performance Management Maturity Model, Infrastructure Optimization Maturity Model, Ladder of Business Intelligence (LOBI) etc. All of these models and case studies of their use are widely described and compared in the available literature and on the websites of their owners, vendors and/or consulting firms applying them (see among others [3], [7], [8], [9], [15], [21], [22], [24], [25]). Because BI Maturity Models primarily assess the maturity of BI solutions used in decision-making processes, BI frameworks are more useful for the evaluation of development projects of the BI application.
BI frameworks are used to compare BI applications, projects and/or vendors. Examples of selected frameworks to the evaluation of BI systems are presented in table 1 .

Generally, BI frameworks define the people, processes, platforms and technologies that need to be integrated and aligned to take a more strategic approach to business intelligence, analytics and performance management initiatives [2, p. 1]. There is no single or right instantiation of the BI frameworks. Different configurations can be supported by the framework based on business objectives and constraints.

Often BI frameworks owners as consulting companies create and provide BI evaluation scorecards. A good example is the BI Scorecard $\AA$ (table 1 ). The BI evaluation scorecard is a tool to support the evaluation process based on the multi-level pre-defined breakdown structure of the evaluation criteria and scoring technique. The changes of the scoring evaluation of BI system/project from the "aswas" to "as-is" and/or "to-be" status can be monitored and visualized and then can be used for the continuous improvement of BI initiatives. The structure and the few elements of BI Scorecard $\AA$ used to evaluate the InKoM system are described in Section IV.

The two last, but not the least, "sources of knowledge" need to create a system of evaluation that - as we noted above - use standards of BI usability/quality and methods/tools dedicated for measurement of economic efficiency of BI systems and/or projects.

In the first area the most important are ISO (IEEE, BSI) standards for software/systems usability/quality evaluation such as "the old" ISO/IEC 9126 (usability), "the new"

TABLE 1.

THE COMPARISON OF SELECTED FRAMEWORKS TO THE EVALUATION OF BI SYSTEMS

\begin{tabular}{|c|c|c|c|}
\hline $\begin{array}{c}\text { Owner and } \\
\text { framework } \\
\text { solution }\end{array}$ & $\begin{array}{c}\text { Gartner } \\
\text { (Business Intelligence and Analytics } \\
\text { Platforms Magic Quadrant and Gartner's } \\
\text { Business Analytics Framework) } \\
\text { (see [2], [26]) }\end{array}$ & $\begin{array}{c}\text { Dresner Advisory Services } \\
\text { (Small and Mid-Sized Enterprise Business } \\
\text { Intelligence Market Study) } \\
\text { (see [31], [32], [33]) }\end{array}$ & $\begin{array}{c}\text { BI Scorecard }{ }^{\circledR} \\
(\text { BI Scorecard Evaluation Frameworks) } \\
(\text { see }[13],[14])\end{array}$ \\
\hline 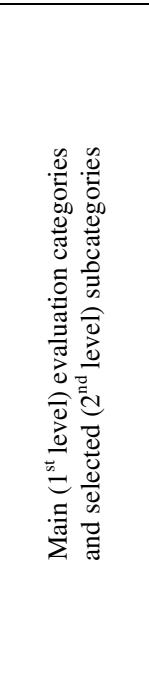 & $\begin{array}{l}\text { 1. Integration: } \\
\text { 1.1.BI infrastructure } \\
\text { 1.2.Metadata management } \\
\text { 1.3.Development tools } \\
\text { 1.4. Collaboration } \\
\text { 2. Information Delivery } \\
\text { 2.1.Reporting } \\
\text { 2.2.Dashboards } \\
\text { 2.3.Ad hoc query } \\
\text { 2.4.Microsoft Office integration } \\
\text { 2.5.Search-based BI } \\
\text { 2.6.Mobile BI } \\
\text { 3. Analysis } \\
\text { 3.1. Online analytical processing } \\
\quad \text { (OLAP) } \\
\text { 3.2.Interactive visualization } \\
\text { 3.3.Predictive modeling and data } \\
\quad \text { mining } \\
\text { 3.4.Scorecards } \\
\text { 3.5.Prescriptive modeling, simulation } \\
\quad \text { and optimization }\end{array}$ & $\begin{array}{l}\text { 1. Ability to write to transactional } \\
\text { applications } \\
\text { 2. Ad-hoc query } \\
\text { 3. Advanced visualization } \\
\text { 4. Big data support } \\
\text { 5. Collaborative support for group-based } \\
\text { analysis } \\
\text { 6. Complex event processing } \\
\text { 7. Data mining and advanced algorithms } \\
\text { 8. Data visualization } \\
\text { 9. End user "self-service" } \\
\text { 10. In-memory support } \\
\text { 11. Interactive analysis } \\
\text { 12. Personalized dashboards } \\
\text { 13. Pre-packaged } \\
\text { 14. Vertical/functional analytical } \\
\text { 15. Production reporting } \\
\text { 16. Social media analysis (Social BI) } \\
\text { 17. Text analytics/Data integration/Data } \\
\text { 18. "Emality tools/ETL }\end{array}$ & $\begin{array}{l}\text { 1. Information delivery and business } \\
\text { intelligence reach } \\
\text { 2. Business query and reporting } \\
\text { 3. Production reporting } \\
\text { 4. OLAP support } \\
\text { 5. Dashboard capabilities } \\
\text { 5.1.Dashboard layout } \\
\text { 5.2.Dashboard design } \\
\text { 5.3.Presentation } \\
\text { 5.4.Alerting } \\
\text { 5.5.Analysis } \\
\text { 5.6.KPIs/metrics } \\
\text { 5.7.Dashboard interactivity } \\
\text { 5.8.Delivery } \\
\text { 5.9.Architecture } \\
\text { 5.10. Other } \\
\text { 6. Delivery and Exploration } \\
\text { 7. Spreadsheet Integration }\end{array}$ \\
\hline
\end{tabular}


SQuaRE (Systems and software Quality Requirements and Evaluation) ISO/IEC 25000:2014, 25010:2011, 25051:2014 and ISO 9241-171:2008 (ergonomics of human-system interaction). The ISO standards defined usability as the software's capacity to be understood, learned, used, and to be attractive to the user in specific use conditions. ISO also establishes four basic principles on which usability is based: ease of learning, ease of use, flexibility, and robustness. These principles were used in the heuristic evaluation of user interface (e.g. dashboards) based on topic maps and visual navigation as a part of the InKoM system usability evaluation [5, pp. 50-58].

The important part of the BI evaluation framework concerns the economic efficiency/effectiveness of BI systems and/or projects (see among others [10], [30]). From this point of view, the evaluation of a given solution represents a process of analysis of costs, benefits and risks, of BI solution, which must be done by a team of both business and IT personnel. The initial evaluation is followed by a series of analyses made before the start of the project (a priori) and after each year of use in order to verify the initial estimation and to adjust the BI solutions.

The main problem that confronts the current frameworks for the measurement of BI solutions is the fact that much of the benefits are strategic benefits, hard to quantify and only appearing several years after the implementation of the solution. Thus, many of the effects of the BI solution are nonfinancial, sometimes intangible effects that lead to financial results after a certain period of time. These benefits come from improved decision-making, and increased quality of information, and often are not financial incomes directly quantifiable (see among others [10], [12], [30]).

There are different methods to evaluate an investment into IT (including BI) solutions. The most important of these is the Cost-Benefits Analysis (CBA) method based on discounted cash flows. CBA used well-known and widely recommended detailed measures and indicators such as IRR (Internal Rate of Return), MIRR (Modified Internal Rate of Return), NPV (Net Present Value) and ROI (Return On Investment). CBA can be extended by the TCO (total cost of ownership) analysis, where TCO/ROI calculators can be used. A good example of such a tool is TDWI Business Intelligence ROI Calculator (www.tdwi.org).

All of these presented "sources of knowledge" are very useful to design multi-criteria evaluation of BI systems and projects. But as a lot of works have noted, most of them are available for large or mid large companies (see among others [9], [23]). However, none of these tools address the project of designing and implementing BI systems in SMEs specifically. Also, there is a lack of guidelines informing how to create BI systems that might be used as reference examples for SMEs.

There is a very important need, because of the role of SMEs as catalysts for the EU (and also Polish) economy, to accelerate SMEs' growth and to improve their competitiveness. This is recognized by the European Commission, which has developed the set of 10 principles to guide the design and implementation of policies both at EU and Member State level, called "Small Business Act" (SBA). The VIII principle of SBA specifies that "The EU and Member States should promote the upgrading of skills in SMEs and all forms of innovation. They should encourage investment in research by SMEs and their participation in R\&D support programmes, transnational research, clustering and active intellectual property management by SMEs" [28].

Therefore in the next section we discuss the extension criteria of BI evaluation frameworks for BI functions oriented on SMEs.

\section{THE INKOM PROJECT AND THE EXTENSION CRITERIA OF BI EVALUATION FRAMEWORKS FOR FUNCTIONS ORIENTED ON SMES}

SMEs may differ from larger companies by a number of key characteristics, e.g. resource and knowledge limitations, lack of money, reliance on a small number of customers, and need for multi-skilled employees. Some of the abovementioned characteristics are putting a greater strain on the SMEs, causing the successful implementation of BI to be possibly more challenging in this context.

SMEs are socially and economically important and need tools and solutions to preserve their competitiveness in challenging environments, particularly because they operate in highly competitive, turbulent and uncertain markets. Usually they do not have control or influence over the market and thus they need to adopt a reactive approach and adapt to market changes.

Scarcity of resources is one of the main problems and a typical characteristic of SMEs. In addition also skills are limited, not only among staff, but also owner-managers often do not have enough managerial expertise or organizational capabilities, and this implies poor strategic business planning and human resource management.

Some of the research has mentioned that for a successful BI project implementation and to bring tangible business benefits to SMEs in the future, it is necessary to meet the following critical success factors: well defined business problem and processes, well defined users' expectations, adjusting the BI solution to users' business expectations, integration between the BI system and other systems, data quality and the flexibility and responsiveness of BI on users' requirements, appropriate technology and tools, and "user friendly"/usability of BI system (see among others [9], [23]).

The analyses presented in the report "Small and MidSized Enterprise Business Intelligence Market Study" specified that "making better decisions" was the mostsought outcome of BI, but SMEs show an even higher regard for revenue growth and competitive advantage stemming from Business Intelligence than their larger peers 
[33, p. 15]. The technology priority changes among SMEs 2012-2013. Only three technologies related to BI increased in importance over 2012: Software-as-a-Service (Cloud BI), Dashboards, and Mobile Device Support [33, p. 25]. For 2013, top technologies related to BI in SMEs included: Dashboards, End User "Self-Service", Advanced Visualization and Data Warehousing. [33, p. 35-36]. The same survey noted that at SMEs, Executive Management, Sales, Finance, and Strategic Planning are most likely to drive BI initiatives and projects. Small Enterprises of one to 100 employees are the most likely of all to see Business Intelligence driven by Executive Management (which might describe CEO, CFO, COO or other titles) and are more likely to be driven from the Sales function [33, p. 26].

Features of SMEs and analysis of the BI market for SMEs indicate the directions of the development of modern BI systems. These directions are included in the InKoM project. In the development of InKoM, many new features are integrated, such as domain ontology covering key concepts of corporate finance and economics, knowledge discovery algorithms, semantic search mechanisms, explanation facilities, and tools for visual navigation in domain knowledge.

One of the main parts of modern BI systems is the ontology. In general, the ontology is used to define the necessary knowledge (see [19], [20]).

In the InKoM project, six ontologies were built, covering economic and financial areas: Cash Flow at Risk, Comprehensive Risk Measurement, Early Warning Models, Credit Scoring, the Financial Market, and General Financial Knowledge. Integration of these ontologies into the BI systems assures:

- support for the definition of business rules in order to get proactive information and advice in decision-making;

- a semantic layer describing relationships between the concepts and indicators;

- relevant information according to the different kinds of users that can be found in an organization;

- effective usage of existing data sources and data warehouse structure [20].
All of these benefits require the extension of the evaluation criteria of BI systems for domain-ontologies category.

The knowledge representation layer is the most critical aspect of a BI system, since it broadly shapes the core understanding of the information displayed on their screen [34]. In InKoM design, the basic assumption of navigation was that managers should be able to view focus and context areas at the same time to present the relevant knowledge structure.

Visual exploration in InKoM (see figure 2) is based on a standard Topic Map (TM - ISO/IEC 13250:2003). TM enables the representation of complex structures of knowledge bases and the delivery of a useful model of knowledge representation, where multiple contextual indexing can be used. Developed topic maps for analysis of economic indicators (see among others [5], [6], [16], [19], [20]) have demonstrated that the system [4]:

- can be easily used for the representation of economic knowledge about economic and financial measures,

- can express the organizational structure,

- can be adapted to new applications and managers' needs,

- can be supportive of the managerial staff by facilitating access to a wide range of relevant data resources,

- can assure a semantic information search and interpretation for non-technically-minded users,

- can visualize different connections between indicators that make possible the discovery of new relations between economic ratios constituting knowledge still unknown in this area,

- can improve the process of data analysis and reporting by facilitating the obtaining of data from different databases in an enterprise, and finally

- can be easily extended by users who are not IT specialists, e.g. by experts in economic analysis (using tools for creating a topic map application).

In turn, this group of features and benefits requires the extension of the evaluation criteria of BI on visual navigation and a data exploration interface based on standard topic maps categories.

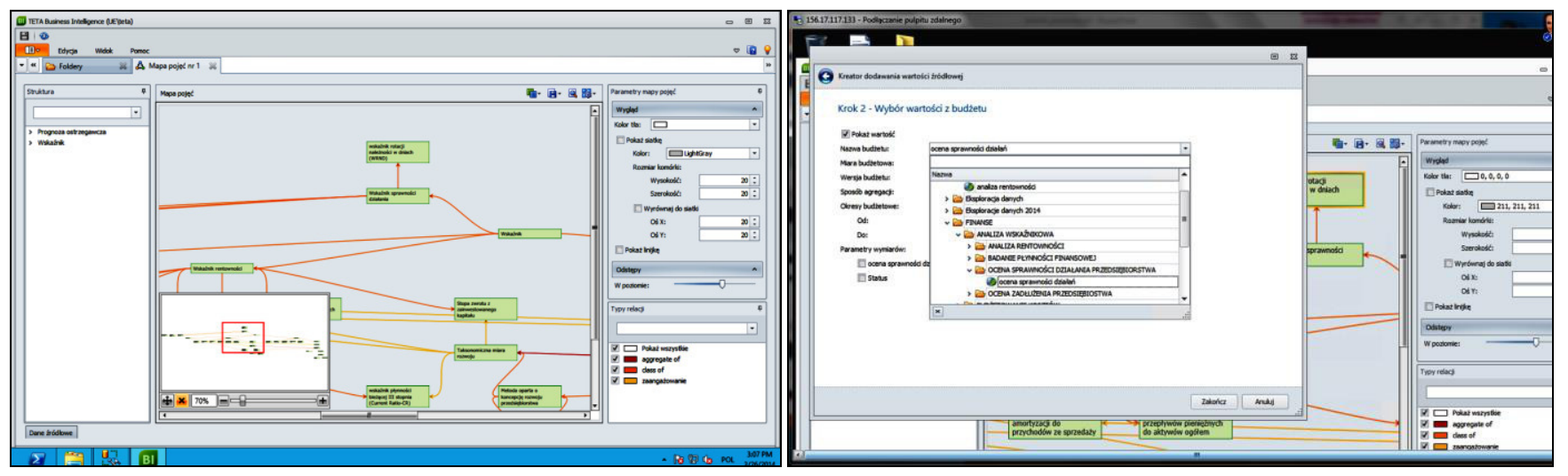

Fig. 2. The visual navigation and data exploration interface of the InKoM system based on topic maps with additional tools and wizards 
This is very important in the case of SMEs, where a company does not employ experts in economic-financial analysis and using external consulting is too costly. Reproducing knowledge with the use of a topic map contributes inter alia to a better understanding of economic concepts and the interpretation of specific economic and financial indicators.

Data exploration algorithms (such as classification trees, association rules methods, clustering) have been integrated with topic maps (i.e. semantic search and visual data exploration). In general, data mining tools currently available on the market contain many knowledge extraction algorithms, but a lot of them are not applicable for SMEs. Moreover some of them are too complex and their usage requires costly expert support.

The data exploration module in InKoM not only is integrated with topic maps/ontologies and contains data exploration methods and algorithms dedicated for SMEs, but also is simple to use for non-analysts. Managers in the data exploration process use the built-in wizards to build step by step data mining models (see figure 3 ).

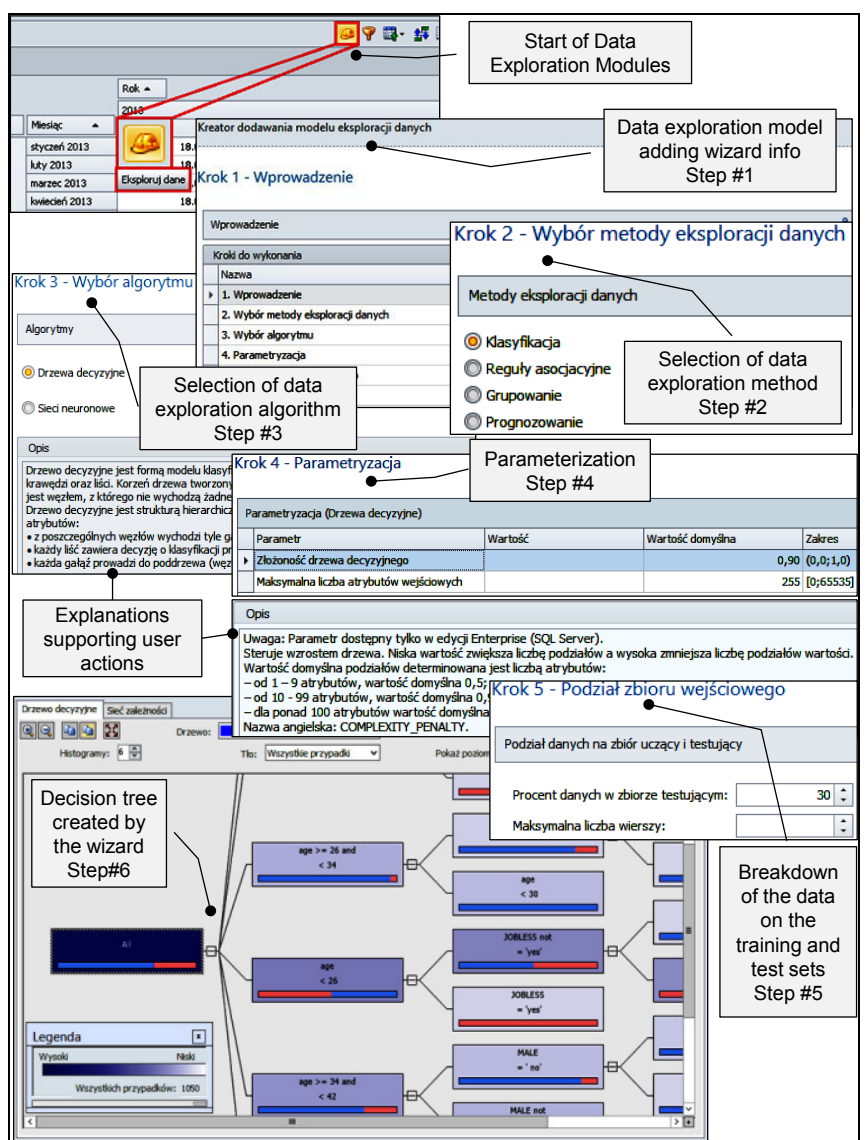

Fig. 3. Data exploration module wizard

These features require the extension of the evaluation criteria of BI related to topic maps/ontologies, dedicated to SMEs' exploration methods and built-in wizards.

\section{CASE StUdy - Evaluation OF INNOVATIVE FUNCTIONS OF THE INKOM DASHBOARD}

Evaluation of the InKoM Dashboard based on categories and subcategories used in BI Scorecard $\AA$ with extensions was defined in the section III. All ratings were exposed using an approach based on the Delphi method. "As-was" assessment was issued on the basis of self-assessment by TETA BIC specialists. In turn, "as-is" assessment was prepared on the basis of internal expertise (developed by InKoM project teams from TETA BIC and WUE) and external expertise (developed by experts from universities and/or research centers and SME's managers). The results of the evaluation are presented in figures: 4 (business query and reporting category), 5 (delivery and exploration category), 6 (information delivery \& BI reach category) and 7 (dashboard category). The detailed requirements for dashboard evaluation are reported in the tables $2 \div 10$, namely:

- the dashboard layout category evaluation (table 2),

- the dashboard design category evaluation (table 3),

- the presentation category evaluation (table 4),

- the alerting category evaluation (table 5),

- the analysis category evaluation (table 6),

- the KPIs / metrics category evaluation (table 7),

- the dashboard interactivity category evaluation (table 8),

- the architecture category evaluation (table 9),

- the delivery and other category evaluation (table 10).

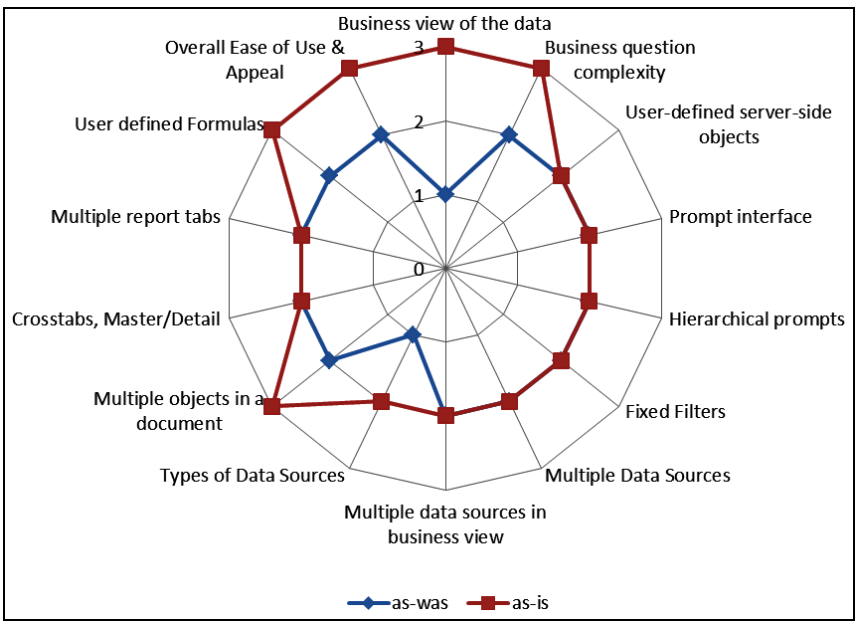

Fig. 4. The results of business query and reporting category evaluation of the InKoM project. Scoring changes from the TETA BI system (as-was) to TETA BI with InKoM functionalities (as-is) 


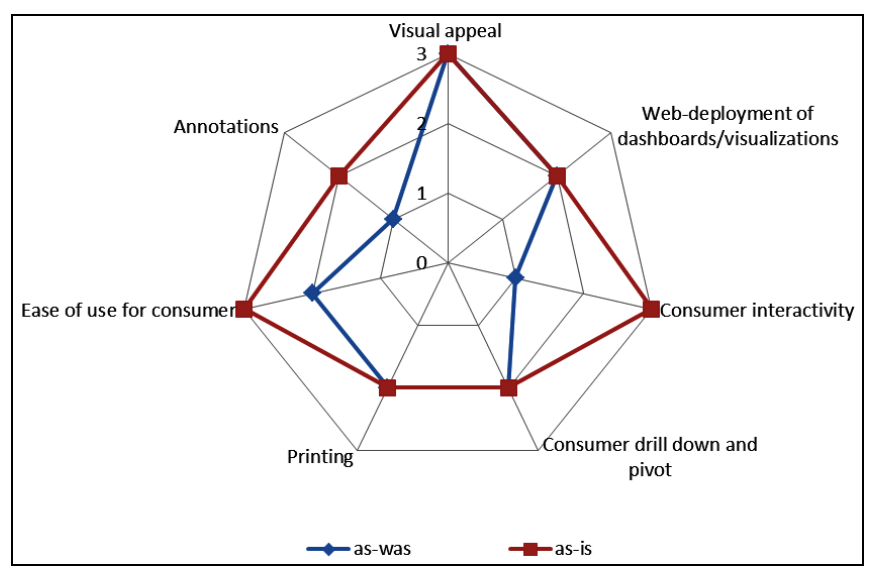

Fig. 5. The results of delivery and exploration category evaluation of the InKoM project. Scoring changes from the TETA BI system (as-was) to TETA BI with InKoM functionalities (as-is)

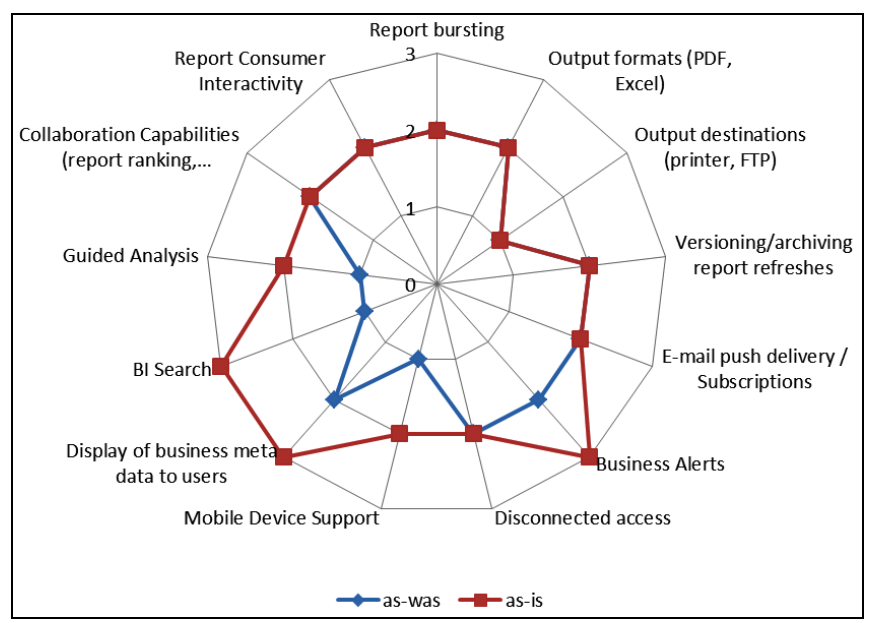

Fig. 6. The results of information delivery \& BI reach category evaluation of the InKoM project. Scoring changes from the TETA BI system (as-was) to TETA BI with InKoM functionalities (as-is)

Table 2.

THE DASHBOARD LAYOUT CATEGORY EVALUATION DETAILED REQUIREMENTS

\begin{tabular}{|l|c|c|}
\hline \multicolumn{1}{|c|}{ Dashboard Layout - detailed requirements } & as-was & as-is \\
\hline Multiple objects on a page/display & 2 & 3 \\
\hline Ability to resize portal objects independently & 2 & 2 \\
\hline $\begin{array}{l}\text { User defined dashboard layout, in addition to } \\
\text { centrally built by IT }\end{array}$ & 2 & 3 \\
\hline $\begin{array}{l}\text { Multiple data sources within dashboard } \\
\text { presentation }\end{array}$ & 2 & 3 \\
\hline \multicolumn{1}{|c|}{ Average value } & $\mathbf{2 , 0 0}$ & $\mathbf{2 , 7 5}$ \\
\hline
\end{tabular}

Table 3.

THE DASHBOARD DESIGN CATEGORY EVALUATION DETAILED REQUIREMENTS

\begin{tabular}{|c|c|c|}
\hline Dashboard Design - detailed requirements & as-was & as-is \\
\hline Formatting templates for consistent look & 0 & 1 \\
\hline WYSIWYG design mode & 2 & 2 \\
\hline Structure mode for faster design without all data & 1 & 2 \\
\hline Record limit in design mode & 2 & 2 \\
\hline Undo & 0 & 1 \\
\hline $\begin{array}{l}\text { Java development environment or Visual Studio } \\
\text { or SDK for embedding }\end{array}$ & 2 & 2 \\
\hline $\begin{array}{l}\text { Developer-defined calcs for data not in data } \\
\text { warehouse }\end{array}$ & 0 & 1 \\
\hline Elements re-usable in multiple dashboards & 2 & 3 \\
\hline Web-based design environment & 0 & 1 \\
\hline Ease of design and maintenance aspects & 2 & 3 \\
\hline Average value & 1,10 & $\mathbf{1 , 8 0}$ \\
\hline
\end{tabular}

Table 4.

The PRESENTATION CATEGORY EVALUATION DETAILED REQUIREMENTS

\begin{tabular}{|l|c|c|}
\hline \multicolumn{1}{|c|}{ Presentation - detailed requirements } & as-was & as-is \\
\hline $\begin{array}{l}\text { Conditional formatting - traffic lights, trend } \\
\text { arrows, highlighting of exceptions and variances } \\
\text { within tabular display }\end{array}$ & 2 & 3 \\
\hline Charts Overall & 2 & 2 \\
\hline Hi/Lo Chart & 2 & 2 \\
\hline Gauge Chart & 2 & 2 \\
\hline Bullet Graphs & 0 & 0 \\
\hline Spark Lines & 0 & 1 \\
\hline Maps Average value & 1 & 2 \\
\hline Ability to create own visualizations & 1 & 2 \\
\hline \multicolumn{2}{|c|}{ Ava } & $\mathbf{1 , 7 5}$ \\
\hline
\end{tabular}

Table 5.

THE AlERTING CATEGORY EVALUATION DETAILED REQUIREMENTS

\begin{tabular}{|l|c|c|}
\hline \multicolumn{1}{|c|}{ Alerting - detailed requirements } & as-was & as-is \\
\hline Alerts - Visual display of exception values or text & 2 & 3 \\
\hline Alerts - Email notification & 2 & 2 \\
\hline $\begin{array}{l}\text { Alerts - user defined in addition to centrally } \\
\text { defined }\end{array}$ & 2 & 3 \\
\hline $\begin{array}{l}\text { Alert as RSS feed or textual display within } \\
\text { dashboard }\end{array}$ & 0 & 0 \\
\hline \multicolumn{1}{|c|}{ Average value } & $\mathbf{1 , 5 0}$ & $\mathbf{2 , 0 0}$ \\
\hline
\end{tabular}

Table 6.

THE ANALYSIS CATEGORY EVALUATION DETAILED REQUIREMENTS

\begin{tabular}{|l|c|c|}
\hline \multicolumn{1}{|c|}{ Analysis - detailed requirements } & as-was & as-is \\
\hline This Year/Last Year analysis & 2 & 3 \\
\hline Top 10 ranking & 2 & 2 \\
\hline $\begin{array}{l}\text { Asymmetrical reporting (expand Q4, collapse } \\
\text { Q1-Q3) }\end{array}$ & 1 & 2 \\
\hline Predictive analysis / what if & 0 & 2 \\
\hline Advanced analysis (based on data exploration) & 0 & 2 \\
\hline \multicolumn{1}{|c|}{ Average value } & $\mathbf{1 , 0 0}$ & $\mathbf{2 , 2 0}$ \\
\hline
\end{tabular}


Table 7.

THE KPIS / METRICS CATEGORY EVALUATION DETAILED REQUIREMENTS

\begin{tabular}{|l|c|c|}
\hline \multicolumn{1}{|c|}{ KPIs / metrics - detailed requirements } & as-was & as-is \\
\hline Web-based screen for users to enter target for KPI & 0 & 1 \\
\hline Multiple targets per metrics (stretch goals) & 2 & 3 \\
\hline User-defined KPIs & 2 & 3 \\
\hline IT-developed KPIs as part of dashboard & 1 & 1 \\
\hline Predefined KPIs / metrics dedicated for managers & 1 & 3 \\
\hline Average value & $\mathbf{1 , 2 0}$ & $\mathbf{2 , 2 0}$ \\
\hline
\end{tabular}

Table 8.

THE DASHBOARD INTERACTIVITY CATEGORY EVALUATION DETAILED REQUIREMENTS

\begin{tabular}{|l|c|c|}
\hline \multicolumn{1}{|c|}{$\begin{array}{c}\text { Dashboard Interactivity - detailed } \\
\text { requirements }\end{array}$} & as-was & as-is \\
\hline Global filter for all gadgets in dashboard & 0 & 0 \\
\hline $\begin{array}{l}\text { Re-sort data in a table within an existing } \\
\text { dashboard }\end{array}$ & 2 & 2 \\
\hline Drill-down & 2 & 3 \\
\hline Pivot / drill by other dimensions & 2 & 3 \\
\hline $\begin{array}{l}\text { Drill from one dashboard to another with context } \\
\text { passed }\end{array}$ & 0 & 1 \\
\hline Sliders / Lassos to select content & 0 & 0 \\
\hline Flash animation & 0 & 0 \\
\hline Overall usability and navigation & 2 & 3 \\
\hline $\begin{array}{l}\text { Interactivity based on new visual tools (topics } \\
\text { maps) }\end{array}$ & $\mathbf{0}$ & $\mathbf{3}$ \\
\hline \multicolumn{1}{|c|}{ Average value } & $\mathbf{0 , 8 9}$ & $\mathbf{1 , 6 7}$ \\
\hline
\end{tabular}

Table 9.

THE ARCHITECTURE CATEGORY EVALUATION DETAILED REQUIREMENTS

\begin{tabular}{|l|c|c|}
\hline \multicolumn{1}{|c|}{ Architecture - detailed requirements } & as-was & as-is \\
\hline Caching - consistently fast response time & 2 & 3 \\
\hline Auto refresh/requery of dashboard objects & 2 & 2 \\
\hline In-memory & 0 & 0 \\
\hline Web-based dashboard delivery & 1 & 2 \\
\hline $\begin{array}{l}\text { Broad and Flexible data access (OLAP, } \\
\text { relational, Web-Services, deep Internet) }\end{array}$ & 2 & 3 \\
\hline $\begin{array}{l}\text { Dashboard integration with other tools in the BI } \\
\text { Suite }\end{array}$ & 2 & 3 \\
\hline \multicolumn{1}{|c|}{ Average value } & $\mathbf{1 , 5 0}$ & $\mathbf{2 , 1 7}$ \\
\hline
\end{tabular}

Table 10.

THE DELIVERY AND OTHER CATEGORY EVALUATION DETAILED REQUIREMENTS

\begin{tabular}{|c|c|c|}
\hline Delivery and other - detailed requirements & as-was & as-is \\
\hline Print whole dashboard & 2 & 2 \\
\hline Export to PDF & 2 & 2 \\
\hline Export to Excel & 2 & 2 \\
\hline Disconnected access & 0 & 1 \\
\hline Live Excel connectivity & 0 & 0 \\
\hline Guided analysis / workflow / link reports & 1 & 2 \\
\hline Annotations /Collaboration & 1 & 2 \\
\hline Integration with ontologies and topic maps & $\mathbf{0}$ & 3 \\
\hline Average value & $\mathbf{1 , 0 0}$ & $\mathbf{1 , 7 5}$ \\
\hline
\end{tabular}

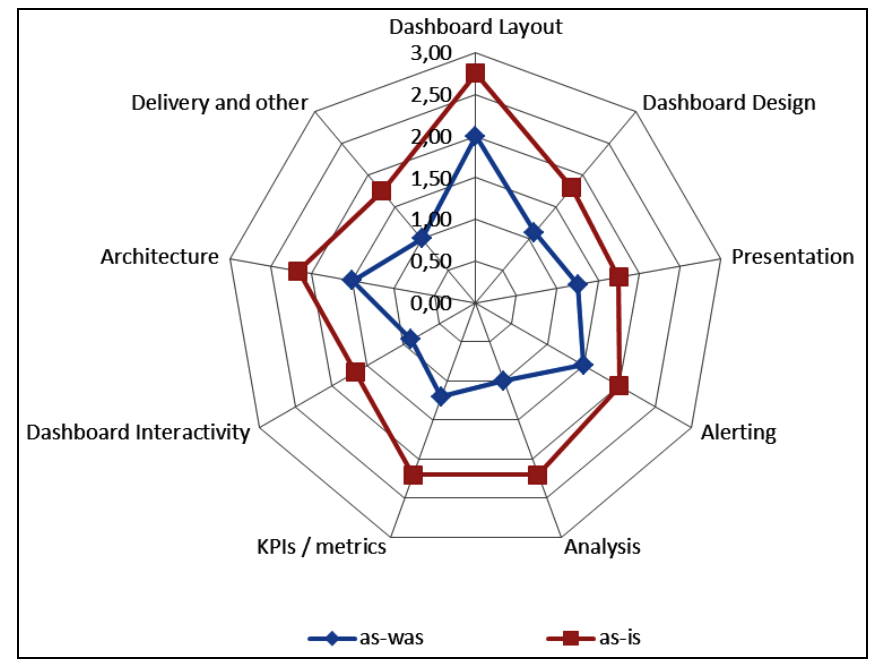

Fig. 7. The results of Dashboard category evaluation of the InKoM project. Average value of detailed requirements (see tables $2 \div 10$ ) of scoring changes from the TETA BI system (as-was) to TETA BI with InKoM functionalities (as-is)

The evaluation of the InKoM system, especially the dashboard categories and subcategories (see the "greyed" cells), shows necessities for improvement of the BI evaluation frameworks and their customization to SMEs solutions and new innovative technologies and concepts.

\section{SUMMARY AND FUTURE WORKS}

In this paper, the multi-criteria evaluation of the Intelligent Dashboard for SME Managers used in the InKoM project environment was presented. Further studies will be conducted on empirical verification of the created framework in "real" SMEs, extension of the evaluation categories to support CBA analysis and measurement of ROI/TCO, and creation of a community of experts to continuously extend and update the evaluation tools.

\section{REFERENCES}

[1] Architektura systemu. TETA Business Intelligence. Materialy informacyjne, UNIT4 TETA Business Intelligence Center, Wrocław 2011.

[2] Chandler N., Hostmann B., Rayner N., Herschel G., Gartner's Business Analytics Framework, Gartner, Inc. no. G00219420, 20 September 2011, http://www.gartner.com/imagesrv/summits/docs/na/businessintelligence/gartners_business_analytics__219420.pdf.

[3] Describing the BI journey. The HP Business Intelligence (BI) Maturity Model. White paper no. 4AA3-9723EEW, created June 2012, http://h20195.www2.hp.com/v2/GetPDF.aspx\%2F4AA3-9723EEW.pdf

[4] Dudycz H., "The concept of using standard topic map in Business Intelligence system", in: Proceedings of the $5^{\text {th }}$ International Conference for Entrepreneurs, Innovation and Regional Development - ICEIRD 2012, D. Birov, Y. Todorova, eds., St. Kliment Ohridski University Press, Sofia, Bulgaria 2012, pp. 228-235.

[5] Dudycz H., "Research on usability of visualization in searching economic information in topic maps-based application for return on investment indicator", in: Advanced Information Technologies for 
Management - AITM'2011. Intelligent Technologies and Applications, J. Korczak, H. Dudycz, M. Dyczkowski, Eds., Wroclaw University of Economics Research Papers no 206, Wrocław 2011, pp. 45-58.

[6] Dudycz H., "Visualization methods in Business Intelligence systems an overview", in: Business Informatics (16). Data Mining and Business Intelligence, J. Korczak Ed., Research Papers of Wroclaw University of Economics, 2010, no. 104, pp. 9-24.

[7] Eckerson W., Business Intelligence Maturity Model, The Data Warehousing Institute TDWI, 1 March 2006, http://www.eurim.org.uk/activities/ig/voi/03-0106_Executive_Series_Assessing_Your_BI_Maturity.pdf

[8] Farrokhi V., Pokorádi L., "The necessities for building a model to evaluate Business Intelligence projects - Literature Review", International Journal of Computer Science \& Engineering Survey (IJCSES), vol. 3, no. 2, April 2012, pp. 1-10.

[9] Fedouaki F., Okar Ch.,, El Alami S., "A maturity model for Business Intelligence System project in Small and Medium-sized Enterprises: an empirical investigation", IJCSI International Journal of Computer Science Issues, vol. 10, issue 6, no 1, November 2013, pp. 61-69.

[10] Ghilic-Micu B., Stoica M., Mircea M., "A framework for measuring the impact of BI solution", in: Proceedings of the 9th WSEAS International Conference on Mathematics \& Computers in Business and Economics (MCBE '08), 2008, http://www.wseas.us/elibrary/conferences/2008/bucharest/mcbe/10mcbe.pdf

[11] Gibcus P., Vermeulen P.A.M., Jong J.P.J., "Strategic decision making in small firms: a taxonomy of small business owners", International Journal of Entrepreneurship and Small Business, vol. 7, no. 1, 2009, pp. 74-91.

[12] Gibson M., Arnott D., Jagielska I., Evaluating the Intangible Benefits of Business Intelligence: Review \& Research Agenda, Decision Support Systems Laboratory, 2004, pp. 295-305.

[13] Howson C., Successful Business Intelligence: Secrets to Making BI a Killer Application, McGraw-Hill, New York, 2008.

[14] Howson C., Successful Business Intelligence, Second Edition: Unlock the Value of BI \& Big Data, McGraw-Hill Education, New York, 2013.

[15] Hribar Rajterič I., "Overview of Business Intelligence Maturity Models", Management, vol. 15, no 1, 2010, pp. 47-67.

[16] Korczak J., Dudycz H., "Approach to visualization of financial information using topic maps", in: Information Management, B. F. Kubiak, A. Korowicki, Eds., Gdansk University Press, Gdansk 2009, pp. 86-97.

[17] Korczak J., Dudycz H, Dyczkowski M., "Intelligent Dashboard for SME Managers. Architecture and Functions", in: Proceedings of the Federated Conference on Computer Science and Information Systems FedCSIS 2012. M. Ganzha, L. Maciaszek, M. Paprzycki, Eds., Polskie Towarzystwo Informatyczne, IEEE Computer Society Press, Warsaw, Los Alamitos, CA 2012, pp. 1003-1007.

[18] Korczak J., Dudycz H., Dyczkowski M., "Intelligent decision support for SME managers - project InKoM", Business Informatics (Informatyka Ekonomiczna), no 3 (25), 2012, pp. 84-96.

[19] Korczak J., Dudycz H., Dyczkowski M., "Design of Financial Knowledge in Dashboard for SME Managers", in: Proceedings of the 2013 Federated Conference on Computer Science and Information Systems, M. Ganzha, L. Maciaszek, M. Paprzycki, Eds., Polskie Towarzystwo Informatyczne, IEEE Computer Society Press, Warsaw, Los Alamitos, CA 2013, pp. 1111-1118.

[20] Korczak J., Dudycz H., Dyczkowski M., "Specification of financial knowledge - the case of Intelligent Dashboard for Managers", Business Informatics (Informatyka Ekonomiczna), no 2 (28), 2013, pp. 56-76.
[21] Lahrmann G., Marx F., Winter R., Wortmann F., "Business Intelligence Maturity: Development and Evaluation of a Theoretical Model", in: Proceedings of the 44 Hawaii International Conference on System Science, 2011.

[22] Olszak C., "Assessment of Business Intelligence Maturity in the Selected Organizations", in: Proceedings of the 2013 Federated Conference on Computer Science and Information Systems, M. Ganzha, L. Maciaszek, M. Paprzycki, Eds., Polskie Towarzystwo Informatyczne, IEEE Computer Society Press, Warsaw, Los Alamitos, CA 2013, pp. 951-958.

[23] Olszak C., Ziemba E., "Critical Success Factors for Implementing Business Intelligence Systems in Small and Medium Enterprises on the Example of Upper Silesia, Poland", Interdisciplinary Journal of Information, Knowledge \& Management, vol. 7, 2012, pp. 129-150.

[24] Popovič A., Turk T., Jaklič J., "Conceptual model of business value of business intelligence systems", Management, vol. 15, no 1, 2010, pp. 529.

[25] Raber D., Wortmann F., Winter R., "Towards the Measurement of Business Intelligence Maturity", in: Proceedings of the 21st European Conference on Information Systems, 2013, http://www.staff.science.uu.nl/ Vlaan107/ecis/

[26] Schlegel K., Sallam R.L., Yuen D., Tapadinhas J., Magic Quadrant for Business Intelligence and Analytics Platforms, Gartner, Inc. no. G00239854, 5 February 2013, http://www.walmeric.com/body/pm/ 2013_gartner_magic_quadrant_for_bi_and_analytics.pdf.

[27] TETA Business Intelligence, UNIT4 TETA Business Intelligence Center, http://tetabic.eu/pl/aplikacja.html.

[28] "Think Small First". A "Small Business Act" for Europe. Communication from the Commission of the European Communities COM (2008) 394 final, 25 June 2008, Brussels, http://www.socialeconomy.eu.org/spip.php?article531/COM-20080394-FIN-EN-TXT

[29] We change data into knowledge. TETA Business Intelligence. Materialy informacyjne UNIT4 TETA Business Intelligence Center, Wrocław 2011.

[30] Whittemore B., The Business Intelligence ROI Challenge: Putting It All Together, Business Intelligence Best Practices, 2008, http://www.bibestpractices.com/view/4782

[31] Wisdom of Crowds $\circledast$ Business Intelligence Market Study. 2013 Edition, Licensed to Information Builders, Dresner Advisory Services, LLC, $20 \quad$ May 2013, http://www.informationbuilders.com/tracker/email/new/pdf/2013_wisdo m_of_crowds_bi_market_study.pdf

[32] Wisdom of Crowds $\Theta$ Mobile Computing/Mobile Business Intelligence Market Study. 2013 Edition, Licensed to MicroStrategy, Dresner Advisory Services, LLC, 11 December 2013,https://www.microstrategy.com/Strategy/media/downloads/whitepapers/mobile_dresner-mobile-bi-study-2013.pdf

[33] Wisdom of Crowds $\Theta$ Small and Mid-Sized Enterprise Business Intelligence Market Study. 2013 Edition, Licensed to TIBCO Software, Dresner Advisory Services, LLC, 6 November 2013, http://explore.tibco.com/rs/tibcospotfire/images/Wisdom_of_Crowds_S ME_BI_Report-Licensed_to_TIBCO_Software-Copyright_2013.pdf

[34] Wise L., The emerging importance of data visualization, part 1, October 29, 2008, http://www.dashboardinsight.com/articles/businessperformance-management/the-emerging-importance-of-datavisualization-part-1.aspx. 